archives

of thermodynamics

Vol. 31(2010), No. 4, 25-35

DOI: $10.2478 /$ v10173-010-0025-6

\title{
Thermovision determination of the furnace chamber environment temperature using the technical black- body model
}

\author{
RAFAŁ WYCZÓŁKOWSKI \\ DOROTA MUSIAE*
}

Czestochowa University of Technology, Department of Industrial Furnaces and Environment Protection, ul. J.H. Dąbrowskiego 69, 42-201 Częstochowa, Poland

\begin{abstract}
The article describes the methodology for the determination of ambient temperature for thermovision measurements. The adopted methodology consists in the use of the technical blackbody model. Determining the value of the ambient temperature parameter makes it possible to enhance the accuracy of temperature measurement of objects exposed to strong irradiation using a thermovision camera.
\end{abstract}

Keywords: Temperature measurements; Blackbody; Thermovision

\section{Nomenclature}

$$
\begin{aligned}
& F \quad-\quad \text { area, } \mathrm{m}^{2} \\
& t \quad-\text { temperature, }{ }^{\circ} \mathrm{C} \\
& T \text { - absolute temperature, } \mathrm{K}
\end{aligned}
$$

Greek symbols

$\varepsilon \quad-$ emissivity

$\sigma \quad-\quad$ Boltzmann constant, $\sigma=5.67 \cdot 10^{-8} \mathrm{~W} / \mathrm{m}^{2} \mathrm{~K}^{4}$.

\footnotetext{
${ }^{*}$ Corresponding author. E-mail address: musial@wp.pl
} 


\section{Subscripts \\ atm - atmosphere \\ env - environment \\ fur - furnace \\ ther - thermocouple}

\section{Introduction}

Thermovision cameras have become an increasingly common and available temperature measuring tool over recent several years. This is largely due to the simplicity of performing the measurement itself and the possibility of acquiring knowledge about the distribution of temperature over the whole surface of the area examined. Moreover, the possibility of taking measurements by this technique in a remote manner makes it possible to avoid any disturbances of the temperature field of the surface being examined.

However, the thermovision technique has also its drawbacks. These result from the principle of the measurement itself, which involves the detection of thermal radiation emitted by the surface being examined. The emission of radiation from the surface of a solid body is described by the Boltzmann equation [1,2]:

$$
\dot{Q}=F \sigma \varepsilon T^{4}
$$

The radiation flux, as described by Eq. (1), is called self-emission. However, when examining a surface, its brightness rather that self-emission reaches the thermovision camera's detector. This is the self-emission and secondary radiation coming from the environment of the surface being examined, which is referred to as irradiation. In this situation, in order to take the correct measurement with a thermovision camera, several parameters need to be introduced to the camera's internal setting, such as: the emissivity of the surface to be examined, atmospheric temperature, atmospheric humidity, ambient temperature, and the distance from the object to be examined [3].

The impact of irradiation on the result of thermovision temperature measurement is especially significant for the examinations of objects surrounded by strongly heated walls or other surfaces. An example of this situation are measurements of elements located in the hot chambers of furnaces or boilers. A parameter crucial for the measurement accuracy, which needs to be introduced to the camera's setting, is in this case an ambient 
temperature that is hard to evaluate. This is a hypothetic temperature being a function of temperatures of all surfaces surrounding the element under examination [4]. There are analytical methods for determining this parameter, which involve the analysis of the brightness balances of surrounding surfaces [5]. However, these procedures require knowledge of the geometry and temperature distribution of all surfaces taken into consideration. Obtaining such knowledge is in the majority of cases practically impossible, as a consequence of which these methods, though being obviously correct from the analytical point of view, do not provide the expected results.

\section{Description of the adopted examination method- ology}

An original, totally new methodology for the determination of ambient temperature for thermovision temperature measurements of strongly irradiated objects is put forwards in the present article. The method consists in the use of a thermovision camera and the technical blackbody model for the determination of the value of the parameter concerned. As generally known, the blackbody absorbs wholly the radiation incident to its surface. Therefore, the radiation emitted from the surface of such a body is solely its selfemission, not being affected in any way by irradiation. So, the temperature readouts of an object having the properties of the blackbody, obtained with a thermovision camera, do not depend on the ambient temperature setting.

Making use of this property, by using an appropriate model of such a body, it was decided to determine the substitute ambient temperature for thermovision measurements of an electric furnace chamber. A schematic of the blackbody model used in the investigation is shown in Fig. 1. The model was prepared from a steel tube length approx. $250 \mathrm{~mm}$ and diameter of $50 \mathrm{~mm}$. One end of the tube was closed by welding a $60 \times 120 \mathrm{~mm}$ piece of metal sheet of $10 \mathrm{~mm}$ thickness. The sheet was welded so that its considerable part extended above the tube. Because of such geometry it was assumed that the sheet surface inside the tube had the properties of a blackbody. The sheet surface above the tube, on the other hand, was regarded as a grey body with emissivity of $\varepsilon=0.8$ (the value for oxidized steel sheet [4]). At the present stage of research, no examination of the effect of the plate emissivity magnitude on the accuracy of measurement results was made. One should be aware of the fact that an incorrectly selected emissivity value will contribute to an increase in the measurement 
error. This problem will be the subject of further studies to this effect. If it turns out that the effect of the magnitude of the parameter $\varepsilon$ on the result of furnace temperature measurement is particularly significant, then it will be necessary to determine it by measurement.

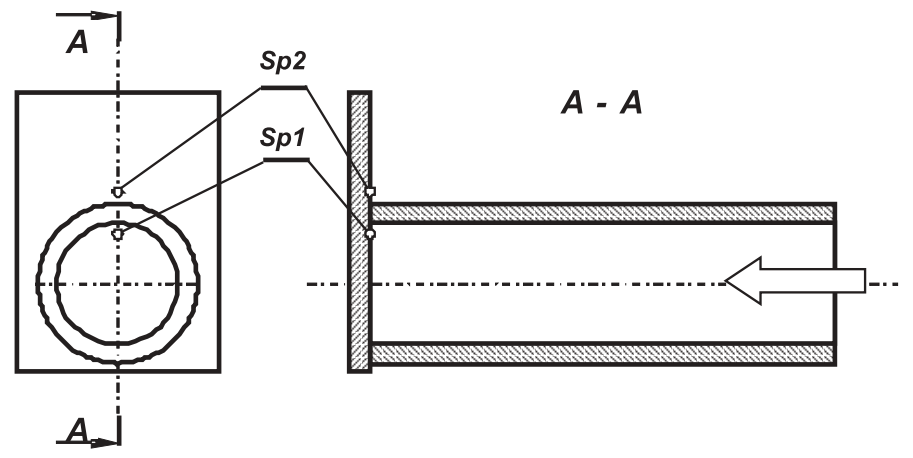

Figure 1. The technical blackbody model used in the tests (the measurement direction is indicated by the arrow).

Thus during investigation the model was placed in the chamber of a laboratory electric furnace by positioning it in such a manner that the tube opening faced towards the furnace door. After heating up the furnace chamber, the temperature of the model was recorded with a thermovision camera. The testing methodology involved the readout of temperature from thermograms for two points lying on the surface of the model under consideration. The location of those points is indicated in Fig. 1 with the symbols Sp1 and $S p 2$. The point $S p 1$ relates to the model surface treated as a blackbody, while the point $S p 2$ to the surface regarded as a grey body. As the considered points are situated very close to each other, it was assumed that they had the identical temperature at a given moment. This assumption can be accepted, because the sheet from the surface of which the temperature was read out is a good thermal conductor.

Further examination involved setting the ambient temperature $t_{e n v}$ for the point Sp2 in the thermovision camera so that the temperature value indicated by the camera at this point was the same as at the point Sp1. This methodology is similar to the method of determining the emissivity in a direct manner using a pyrometer of a thermovision camera $[4,6,7]$. 


\section{Thermovision camera used in the examination}

A ThermaCAM P65 thermovision camera was used for the examination. This is a device operating within the long-wave range of the thermal radiation spectrum $(7.5-13 \mu \mathrm{m})$, equipped with a non-cooled micro-bolometric infrared detector, type FPA (Focal Plane Array). Thermograms are stored in the JPEG format in the camera's internal RAM memory or in a FLASH type memory card. The correct temperature measurement requires information on the following parameters to be entered to the camera's internal program:

- atmospheric temperature, $t_{a t m}$;

- ambient temperature, $t_{e n v}$;

- emissivity, $\varepsilon$, of the object to be examined;

- measuring distance.

The camera comes with specialized software enabling the analysis of thermograms and creation of special test reports. The software allows the determination of the following, among others:

- temperature for any points on the thermogram,

- isothermal regions,

- histograms for any sub-regions on the thermogram,

- the values of the maximum, minimum, and average temperatures for any subregions on the thermogram,

- the profiles of temperature distribution along an arbitrary line passed on the thermograph.

During the analysis of a thermogram, it is possible to change the values of specific parameters, for which that thermogram was recorded. These parameters can be set independently for elements isolated on the same thermogram. For example, for two points on the same thermogram, two different emissivities can be set. It is this possibility that was used in further investigation. 


\section{Measurement process}

A series of thermograms for five different furnace chamber temperatures were recorded during the tests. This parameter, designated by the symbol $t_{f u r}$, was measured with the thermocouple included in the furnace equipment. During the tests, an additional thermocouple was installed in the furnace chamber, whose tip was situated in the geometrical centre of the furnace chamber. The temperature indicated by this sensor is designated by the symbol $t_{t h e r}$. The values of the temperatures $t_{f u r}$ and $t_{t h e r}$, for which respective thermograms were recorded (measurement completions I-V), are summarized in Tab. 1. As can be seen, the values of both parameters differ. Each time, the temperature indicated by the furnace's thermocouple was higher than the temperature of the additional thermocouple. This is due to the fact that the tip of the furnace's thermocouple was positioned close to one of the furnace's walls, immediately between the resistance coils which constituted the heating elements. This caused the sensor to be strongly irradiated, the consequence of which were higher values of the parameter $t_{f u r}$.

Table 1. Values of temperatures $t_{f u r}, t_{t h e r}$ and $t_{e n v}$ for particular measurements.

\begin{tabular}{|l||c|c|c|c|c|}
\hline measurements realization & I & II & III & IV & V \\
\hline \hline$t_{\text {fur }},{ }^{\circ} \mathrm{C}$ & 730 & 760 & 820 & 870 & 900 \\
\hline$t_{\text {ther }},{ }^{\circ} \mathrm{C}$ & 673 & 718 & 772 & 847 & 874 \\
\hline$t_{\text {env }},{ }^{\circ} \mathrm{C}$ & 669 & 723 & 777 & 840 & 880 \\
\hline
\end{tabular}

When carrying out the tests, an analysis was made for each thermogram following the method described in the previous section. On each thermogram, the points $S p 1$ and $S p 2$ were determined in the first place. Then, an emissivity of $\varepsilon=1$ was set for the point $S p 1$, and an emissivity of $\varepsilon=0.8$ for the point $\mathrm{Sp2}$. A sample thermogram, on which the above-mentioned points are indicated, is shown in Fig. 2.

The next step was to search for such a value of ambient temperature for the point $S p 2$ that the temperature indicated for this point was equal to the temperature of the point $S p 1$. When performing the examinations, the atmospheric temperature was also changed. This parameter is defined as the temperature of the medium (gas) that occurs in the measurement path, between the object being examined and the camera lens. However, as has been demonstrated by the obtained results, this parameter does 


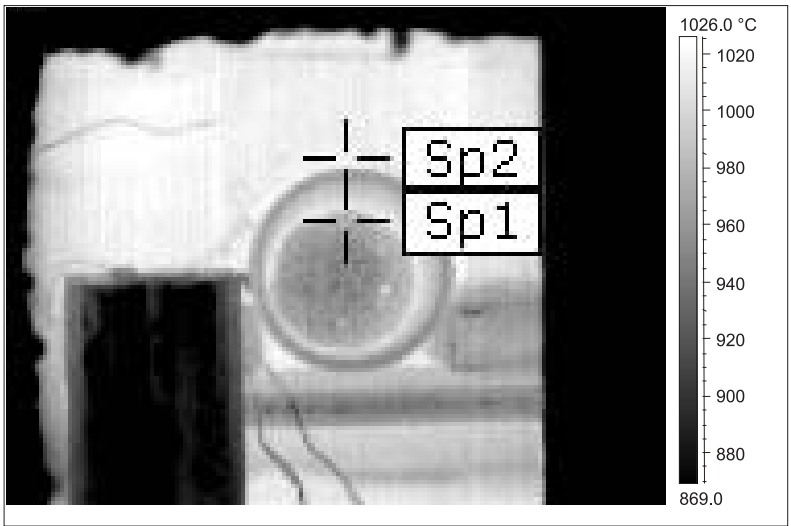

Figure 2. A thermogram with the points $S p 1$ and $S p 2$ indicated within the blackbody model.

not have that great effect on the values of temperatures indicated by the thermovision camera.

\section{Examination results}

The results of the examinations carried out are represented in a tabular form. A separate table has been completed for each thermogram. The analyzes were made for five value of the parameter $t_{e n v}$ and for two values of the atmospheric temperature $t_{a t m}$. The values of temperature $t_{a t m}$ were assumed as the minimum and maximum values of the ambient temperature considered for a particular thermogram. The results obtained for particular measurements (thermograms) are summarized in Tabs. 2-6.

Table 2. Results of the analysis of a thermogram recorded for measurement completion I.

\begin{tabular}{|l||c|c|c|c|c|}
\hline \multicolumn{1}{|c||}{$t_{\text {fur }},{ }^{\circ} \mathrm{C}$} & \multicolumn{5}{c|}{730} \\
\hline$t_{\text {atm }},{ }^{\circ} \mathrm{C}$ & \multicolumn{5}{c|}{640} \\
\hline$t_{\text {env }},{ }^{\circ} \mathrm{C}$ & 640 & 660 & 670 & 680 & 700 \\
\hline $\mathrm{Sp} 1$ & 649.0 & 649.0 & 649.0 & 649.0 & 649.0 \\
\hline $\mathrm{Sp} 2$ & 662.9 & 653.9 & 649.4 & 644.8 & 635.6 \\
\hline$t_{\text {atm }},{ }^{\circ} \mathrm{C}$ & \multicolumn{5}{|c|}{700} \\
\hline$t_{\text {env }},{ }^{\circ} \mathrm{C}$ & 640 & 660 & 670 & 680 & 700 \\
\hline $\mathrm{Sp} 1$ & 647.8 & 647.8 & 647.8 & 647.8 & 647.8 \\
\hline $\mathrm{Sp} 2$ & 661.2 & 652.2 & 647.7 & 643.1 & 633.9 \\
\hline
\end{tabular}


Table 3. Results of the analysis of the thermogram recorded for measurement completion II.

\begin{tabular}{|l|c|c|c|c|c|}
\hline$t_{\text {fur }},{ }^{\circ} \mathrm{C}$ & \multicolumn{5}{|c|}{760} \\
\hline$t_{\text {atm }},{ }^{\circ} \mathrm{C}$ & \multicolumn{5}{|c|}{690} \\
\hline$t_{\text {env }},{ }^{\circ} \mathrm{C}$ & 690 & 710 & 720 & 730 & 750 \\
\hline $\mathrm{Sp} 1$ & 747.9 & 747.9 & 747.9 & 747.9 & 747.9 \\
\hline $\mathrm{Sp} 2$ & 755.7 & 750.8 & 748.4 & 745.9 & 740.9 \\
\hline$t_{\text {atm }},{ }^{\circ} \mathrm{C}$ & \multicolumn{5}{|c|}{750} \\
\hline$t_{\text {env }},{ }^{\circ} \mathrm{C}$ & 690 & 710 & 720 & 730 & 750 \\
\hline $\mathrm{Sp} 1$ & 746.8 & 746.8 & 746.8 & 746.8 & 746.8 \\
\hline $\mathrm{Sp} 2$ & 754.4 & 749.5 & 747.1 & 744.6 & 739.6 \\
\hline
\end{tabular}

Table 4. Results of the analysis of the thermogram recorded for measurement completion III.

\begin{tabular}{|l||c|c|c|c|c|}
\hline \multicolumn{1}{|c||}{$t_{\text {fur }},{ }^{\circ} \mathrm{C}$} & \multicolumn{5}{|c|}{820} \\
\hline$t_{\text {atm }},{ }^{\circ} \mathrm{C}$ & \multicolumn{5}{|c|}{740} \\
\hline$t_{\text {env }},{ }^{\circ} \mathrm{C}$ & 740 & 760 & 770 & 780 & 800 \\
\hline Sp1 & 773.8 & 773.8 & 773.8 & 773.8 & 773.8 \\
\hline Sp2 & 782.6 & 777.6 & 775.1 & 772.6 & 767.6 \\
\hline$t_{\text {atm }},{ }^{\circ} \mathrm{C}$ & \multicolumn{5}{|c|}{800} \\
\hline$t_{\text {env }},{ }^{\circ} \mathrm{C}$ & 740 & 760 & 770 & 780 & 800 \\
\hline Sp1 & 772.9 & 772.9 & 772.9 & 772.9 & 772.9 \\
\hline Sp2 & 781.1 & 776.2 & 773.7 & 771.2 & 766.1 \\
\hline
\end{tabular}

It follows from Tab. 2 that the ambient temperature value has a key influence on the accuracy of measurements of strongly irradiated elements with a thermovision camera. Change in ambient temperature by $60{ }^{\circ} \mathrm{C}$ results in a change in $S p 2$ point temperature by $27.3^{\circ} \mathrm{C}$. Obviously, the temperature of the point $S p 1$ with emissivity equal to 1 is not dependent on the ambient temperature. The atmospheric temperature does not influence the values of temperatures being read out so significantly. With the change of this parameter by $60{ }^{\circ} \mathrm{C}$, the changes in the temperatures of the points $S p 1$ and Sp2 amount to approx. $1{ }^{\circ} \mathrm{C}$. Similar trends occurs for results obtained for the remaining measurements.

The ambient temperatures determined for particular measurements are summarized in the bottom row of Tab. 1. This enables the values of this parameter to be directly compared with the values of temperatures $t_{\text {fur }}$ and $t_{\text {ther }}$. As can be noticed, the ambient temperature value is close to the temperature recorded by the thermocouple positioned in the geometrical centre of the furnace chamber. 
Table 5. Results of the analysis of the thermogram recorded for measurement completion IV.

\begin{tabular}{|l||c|c|c|c|c|}
\hline \multicolumn{1}{|c||}{$t_{\text {fur }},{ }^{\circ} \mathrm{C}$} & \multicolumn{5}{|c|}{870} \\
\hline$t_{\text {atm }},{ }^{\circ} \mathrm{C}$ & \multicolumn{5}{c|}{820} \\
\hline$t_{\text {env }},{ }^{\circ} \mathrm{C}$ & 820 & 840 & 850 & 860 & 880 \\
\hline Sp1 & 838.0 & 838.0 & 838.0 & 838.0 & 838.0 \\
\hline Sp2 & 843.2 & 838.3 & 835.8 & 833.2 & 828.2 \\
\hline$t_{\text {atm }},{ }^{\circ} \mathrm{C}$ & \multicolumn{5}{|c|}{880} \\
\hline$t_{\text {env }},{ }^{\circ} \mathrm{C}$ & 820 & 840 & 850 & 860 & 880 \\
\hline Sp1 & 837.1 & 837.1 & 837.1 & 837.1 & 837.1 \\
\hline Sp2 & 842.1 & 837.1 & 834.6 & 832.1 & 827.0 \\
\hline
\end{tabular}

Table 6. Results of the analysis of the thermogram recorded for measurement completion $\mathrm{V}$.

\begin{tabular}{|l||c|c|c|c|c|}
\hline \multicolumn{1}{|c||}{$t_{\text {atm }},{ }^{\circ} \mathrm{C}$} & \multicolumn{5}{c|}{900} \\
\hline$t_{\text {atm }},{ }^{\circ} \mathrm{C}$ & \multicolumn{5}{c|}{850} \\
\hline$t_{\text {env }},{ }^{\circ} \mathrm{C}$ & 850 & 870 & 880 & 890 & 910 \\
\hline $\mathrm{Sp} 1$ & 852.4 & 852.4 & 852.4 & 852.4 & 852.4 \\
\hline Sp2 & 859.7 & 854.7 & 852.1 & 849.6 & 844.5 \\
\hline$t_{\text {atm }},{ }^{\circ} \mathrm{C}$ & \multicolumn{5}{|c|}{910} \\
\hline$t_{\text {env }},{ }^{\circ} \mathrm{C}$ & 850 & 870 & 880 & 890 & 910 \\
\hline $\mathrm{Sp} 1$ & 851.2 & 851.2 & 851.2 & 851.2 & 851.2 \\
\hline $\mathrm{Sp} 2$ & 858.5 & 853.5 & 851.0 & 848.5 & 843.4 \\
\hline
\end{tabular}

During the test, in addition to the blackbody model, a steel element in the form of a $50 \times 50 \times 100 \mathrm{~cm}$ rectangular prism was also present in the furnace chamber. Based on the thermograms, the surface temperature of this element was determined. A sample thermogram, on which the surface of the element under analysis is denoted by the area Ar1 is shown in Fig. 3. For the area Ar1 the maximum $t_{\text {max }}$, the minimum $t_{\text {min }}$, and the average $t_{\text {ave }}$, temperatures were determined. When making the analysis, the values of summarized in Tab. 1 were substituted for the temperature $t_{e n v}$. The variation of respective temperatures of the area Ar1 as a function of ambient temperature is represented in Fig. 4.

The presented testing results, as any measurement results, are burdened with some error. The magnitude of this error is influenced by two factors. The first one is the measurement accuracy of the equipment used (the thermovision camera and the contact temperature measurement system). The second factor is the accuracy of determination of the emissivity of the surface 


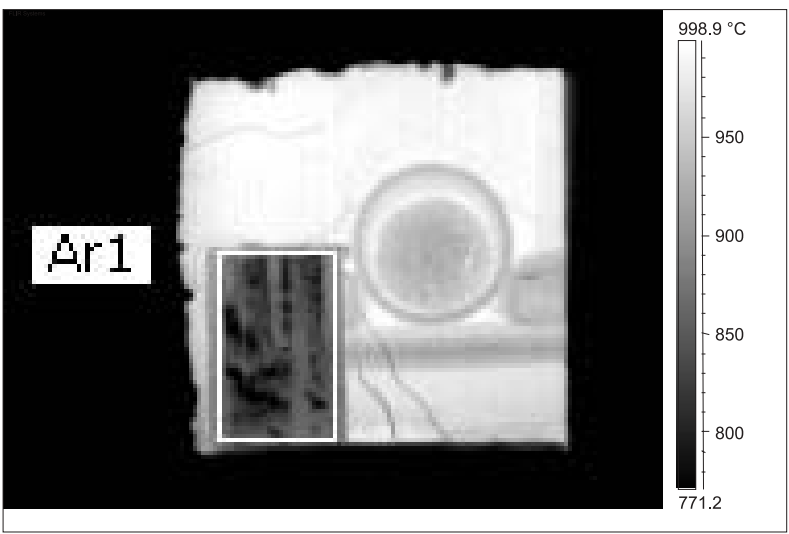

Figure 3. A thermogram of charge heated in the furnace chamber with the Ar1 area marked.

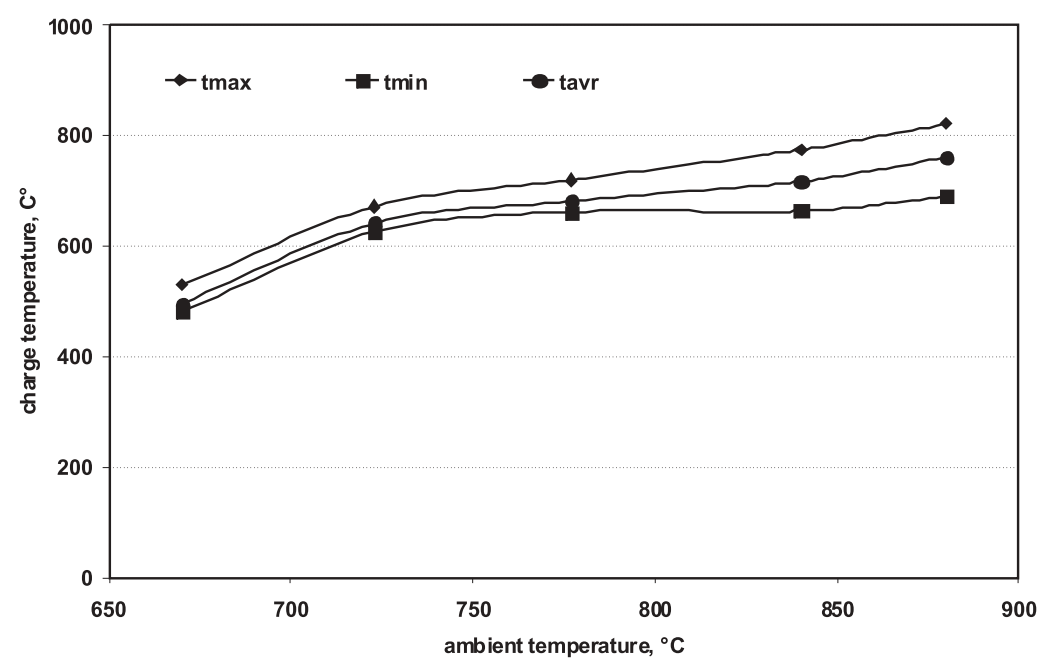

Figure 4. Variation of the mximal, minimal and average temperatures of the area $t$ Ar1 as a function of ambient temperature.

located above the blackbody model. As this is a relatively wide problem area, it has not been addressed due to the limited volume of the paper. This problem will be discussed in detail and in depth by the authors in subsequent publications on the subject. 


\section{Summary}

The article has described a methodology for the determination of ambient temperature being one of the quantities that need to be entered to the internal setting of the thermovision camera. This is done in order to correct the interfering effect of irradiation on the outcome of temperature measurement. The adopted methodology of determining the ambient temperature involves the use of the technical blackbody model. Thus determined value of the parameter ambient temperature, $t_{e n v}$, makes it possible to enhance the accuracy of thermovision camera temperature measurement of objects subject to strong irradiation. Such a situation can be met when taking measurements of the object situated in the heated chambers of plants, such as furnaces, boiler or high-temperature chemical reactors.

It should be mentioned that the presented investigation is preliminary in its character. To verify the accuracy of the proposed method, the authors intend to carry out further studies. Measurements are planned to be performed both in laboratory and in industrial conditions.

Received 28 August 2010

\section{References}

[1] Staniszewski B.: Heat Exchange. Theoretical bases. PWN, Warsaw 1980 (in Polish).

[2] Kostowski E.: Heat Flow. Wydawnictwo Politechniki Śląskiej, Gliwice 2000 (in Polish).

[3] ThermaCAM P65. User Guide. FLIR SYSTEMS, 2004.

[4] Minkina W.: Thermovision measurements - equipment and methods. Wydawnictwo Politechniki Częstochowskiej, Częstochowa 2004.

[5] KRUCZEK T.: Analysis of the possibilities of thermovisual temperature measurement of internal surfaces of boilers and furnaces. XII National Conference "Thermal Management and Operation of Industrial Boilers", Częstochowa 2005, 91-99 (in Polish).

[6] Daniel T., Krężoeek I., Radomiak H., Kupka E.: Emissivity measurement of zinc coated sheet. Hutnik, No. 3, 1999, 121-125 (in Polish).

[7] KruczeK T., Rudnicki Z., SAChajdak A.: Emissivity measurement of steel sheet annealed prior to zinc coating in the furnace with controlled atmosphere. VIII National Conference "Thermal Management and Operation of Industrial Boilers", Poraj 2000, 157-164 (in Polish). 